\title{
Editorial Note: Advances in Visual Analytics and Mining Visual Data
}

(C) Springer Science+Business Media, LLC, part of Springer Nature 2018

Multimedia Tools and Applications gratefully acknowledges the editorial work of the scholars listed below on the special issue entitled, "Advances in Visual Analytics and Mining Visual Data."

Of 63 papers submitted to this issue, 13 were eventually accepted after a stringent peerreview process.

Dr. Shadi A. Aljawarneh (Corresponding Guest Editor)

Associate Professor of Software Engineering

Department of Software Engineering, Faculty of CIT

Jordan University of Science and Technology

Irbid, Jordan

saaljawarneh@just.edu.jo

Dr. Oguz Bayat

Associate Professor

Department of Electrical and Electronics Engineering

Istanbul Kemerburgaz University

Istanbul, Turkey

oguz.bayat@kemerburgaz.edu 